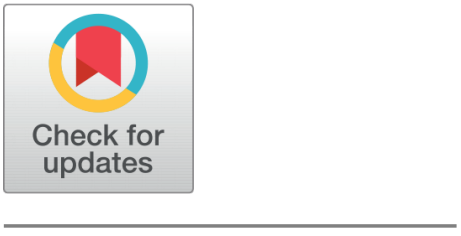

open ACCESS

Received: 11.03.2021

Accepted: 07.04.2021

Published: 26.04 .2021

Citation: Pushpamala Ramaiah, Tayyib NA, Alsolami FJ, Lindsay GM, Asfour HI, Alshmemri MS, Alsulami SA (2021) Generated Themes of E-learning: Exploration of Students' Challenges During Covid-19. Indian Journal of Science and Technology 14(14): 1133-1138. https://doi.org/ 10.17485/IJST/v14i14.425

* Corresponding author.

Tel: +966534318424

aravindanadar@gmail.com

Funding: None

Competing Interests: None

Copyright: ( 2021 Pushpamala Ramaiah et al. This is an open access article distributed under the terms of the Creative Commons Attribution License, which permits unrestricted use, distribution, and reproduction in any medium, provided the original author and source are credited.

Published By Indian Society for Education and Environment (iSee)

ISSN

Print: 0974-6846

Electronic: 0974-5645

\section{Generated Themes of E-learning: Exploration of Students' Challenges During Covid-19}

\author{
Pushpamala Ramaiah ${ }^{1}{ }^{*}$, Nahla A Tayyib ${ }^{1}$, Fatmah J Alsolami ${ }^{1}$, \\ Grace M Lindsay ${ }^{1}$, Hayam I Asfour ${ }^{1}$, Mohammad S Alshmemri ${ }^{1}$, \\ Sanaa A Alsulami ${ }^{1}$ \\ 1 Faculty of Nursing, Umm Al-Qura University, Mecca, 21955, Saudi Arabia. \\ Tel.: +966534318424
}

\section{Abstract}

Objective: To explore the perception of undergraduate nursing students of second-year courses regarding e-learning experiences, competencies, interests, and values and obtain suggestions for improving such practices organized during the pandemic crisis of Covid-19. Methodology: The present crosssectional descriptive study design attempted to investigate the undergraduate nursing students' experiences related to the quality dimensions of e-learning. Data were collected from 121 undergraduate students of a University in Saudi Arabia who completed a set of reflective questions. Findings: Four themes were generated; instructional immediacy, Self-confidence, Innovative navigation, High Versus Low Stakes Assignments, including the advantages, challenges, and recommendations, are also discussed. Novelty: The article demonstrates the domains of challenges that might impact students' experiences during e-learning amid Covid-19.

Keywords: Students experiences; E-learning; Covid-19; quality; generated themes

\section{Introduction}

Computers and instructional technology have become an essential pillar in the 21 st-century classroom. Course content delivery in most college courses has been progressively accomplished by lectures delivered using untraditional in a class format, mostly online ${ }^{(1)}$. Computer and electronic media have played a predominant role in the establishment of e-learning. E-learning is supported by computer-based electronic technologies, which have been rapidly developed in the 21 st-century and have significantly impacted education. The information and communication technology explosion increases digital devices' use for many purposes in work and informal and non-formal education ${ }^{(2)}$. As a result of Covid-19, education has changed dramatically and drastically, with the phenomenal rise of virtual learning, whereby teaching is held remotely. Research suggests that off-campus learning has been practiced to develop information retention and take less time, meaning the impact coronavirus has caused might be here to stay ${ }^{(3)}$. With this sudden transition away from the classroom in many 
parts of the globe, few wonders whether online learning strategies will continue to persist post-pandemic and how such a change would alter the worldwide education market ${ }^{(4)}$. Since the declaration of Covid-19 spread, online classes have become the epic of the education system. The online transition made most universities, colleges, and other educational institutions with lots of challenges as a trial phase of teaching-learning. Online learning provides higher education opportunities to deliver services for people continuing their education, leverage technology to reduce teachers' burden, and use improved pedagogies better suited to maintaining student engagement ${ }^{(5)}$. Nurse Educators are also challenged to teach nursing students to become competent professionals who have both in-depth knowledge and decision-making skills. Electronic learning methods have been found to facilitate the teaching-learning process in nursing education ${ }^{(6)}$. In recent weeks, social distancing restrictions related to the COVID-19 pandemic have profoundly changed how student nurses learn worldwide and, even with distress, a lack of coping. Until the pandemic began, teaching institutions had a history of pushing back against the virtual learning process. In Saudi Arabia, educational institutions have started implementing online learning courses to guide students to succeed and overcome barriers during a pandemic. The Saudi Research and Innovation Network has teamed up with various innovative Integrated technology to support university students and members, raise the quality of virtual classrooms and learning platforms, and improve national digital services access ${ }^{(7)}$.

Blackboard Collaborate is uniquely designed for educators and learners and can ease the transition to a fully digital education environment by offering course capabilities of synchronous and asynchronous perspectives. The e-learning classroom solution connects students and instructors via both desktop and mobile devices. The professional development series ensures instructors can continue to drive students' achievements and maintain the same high-quality instruction as in-class courses by addressing pedagogical and instructional design best practices for digital course development ${ }^{(8)}$. Nevertheless, teaching effectiveness in the online environment is essential in building Social presence and Cognitive presence ${ }^{(9)}$. Moreover, nursing educators should evaluate their teaching and learning style preferences to know their unintended bias towards specific learning and teaching strategies ${ }^{(10)}$. Instructors should establish their involvement in the absence of physical co-presence, build intellectual relationships with students, and create a comfortable environment. It is a balance of student and instructor factors that facilitate faculty and student experiences ${ }^{(11)}$.

Higher education organizations' knowledge and educational needs will not succeed in implementing the e-learning educational system as an effective strategy in managing it without identifying the different skill, technical, and cultural challenges $^{(12)}$.

Many studies have been conducted to explore student nurses' perceptions of the inclusion of intended learning strategies. At the higher education department of health institutions, though most of the students are active users of the internet, emails, and media, they are not familiar with e-learning. Hence, this research has been conducted to interpret students' real current experiences, challenges, and future expectations to gain in-depth insight into the student nurses' perception.

\section{Methodology}

A descriptive cross-sectional study qualitative design was adopted due to the nature of the research objectives. The data were collected from the undergraduate second-year bachelor nursing students related to the quality dimensions of e-learning embracing online interaction focus group sessions. The study used a purposive sampling method of all the students who underwent an e-learning course at a higher education health institution in the department of nursing in Saudi Arabia. A set of five reflective questions were discussed with the purposively sampled students to analyze their experiences during lectures. The discussion included formative tests, summative tests, case scenarios of mini-quiz, and their expectations using semi-structured online focus groups using the Blackboard management system's university portal. Invited participation was voluntary, divided into six focus groups. The study was open to all learners who completed the course in the 2020 summer semester, where the online system was made as a required method of teaching amid COVID-19. Data collection focused on four primary areas, including positive experiences, challenges in communication, motivation, and future recommendations. Online focus group sessions included reflection dialogues and verbatim transcripts, which continued until theoretical saturation was achieved when subsequent meetings do not produce any new information ${ }^{(13)}$. The collected data were processed as (1) Collected data transcribed into verbatim (2) the transcripts were consistently able to recognize and comprehend the sentences formed by appropriate words, phrases, and sentences; (3) meaning units were analyzed and arranged under four themes ${ }^{(14)}$. This research proposal was ethically approved by the Deanship of postgraduate studies\& scientific research, Faculty of Nursing, Umm al-Qura University. 


\section{Data Analysis}

In this qualitative study, the researchers are the research tool directly involved in the research process. Thus, self-reflection is essential to avoid preconceived ideas or roles outside the study from influencing the research process, particularly in the thematic coding and interpretation of interview data. In line with the exercise, we acknowledge that the researchers are nurse educators directly involved in developing the project's content. We may favour e-learning and expect positive outcomes from nursing students. Still, we constantly reminded ourselves that different learners might learn differently from what we consider the ideal learning process. We also agreed that the negative comments critical of e-learning are the unmet needs that we can use to improve our teaching method. The researchers dealt with the data carefully by an interactive reading of data during the data analysis phase. However, the research team members were not involved in the transcribing process due to the potential bias.

Data was collected and analyzed by the systemic phases of thematic analysis. To be accepted as trustworthy, qualitative researchers must demonstrate that data analysis has been conducted in a precise, consistent, and exhaustive manner by documenting, systematizing, and disclosing analysis methods with appropriate detail to enhance readers to determine whether the process is credible ${ }^{(15)}$.

\section{Results}

Within one course, all 121 students participated and completed the data collection by online interview (focus group) method using an anonymous set of reflective open-ended questions. All were included in the analysis. Four themes were generated:

- Instructional immediacy,

- Self-confidence,

- Innovative navigation, and

- High Stakes versus Low Stakes Assignments.

\subsection{Instructional Immediacy}

"E-learning motivates us to learn because when we are given a scenario from a case study, we learn from history, physical examination, and then the nursing diagnosis. If we are not quite sure, we can go back to our textbooks to refer to the actual and potential nursing diagnosis that forces us indirectly to broaden our analytical domain." (FG 1 and 2)

In essence, they verbalized feeling isolated or insecure and participated less in the course if immediate feedback on any exciting issue is not obtained. (FG 1, 2 and 3)

E-learning encourages fostering interaction with the educator-flexibility in communication act as a source of motivation in the course. (FG 3 and 4)

"Using BBLMS It is good, and it is quite encouraging to be able to have more frequent discussions with the instructor." (FG 5 and 6)

Many focus group students documented "verbal immediacy by referring it to calling the students by name, using humour, and encouraging students' input and discussion." (FG 4, 5, and 6).

\subsection{Self-Confidence}

Students believed that being self-confident does not mean that they overlook their weaknesses and focus only on their strengths. The transition from traditional to online learning prompted students to analyze their habits and behaviours to determine their shortcomings. Because they underwent unique technology (BBLMS) learning due to the pandemic Covid-19 crisis, which was also an opportunity to complete their courses successfully instead of extending or delaying the course. Students expressed three main ways in which they thought technologies revamped their self-confidence: enabling better communication with and learning from trainers, getting prompt and detailed feedback from staff, and helping students to put their learning into context.

"Institutional, technological support facilitates in providing one-to-one support to students who struggle with concerns of anxiety, helping to develop their confidence and self-esteem and re-engage with learning." (FG 1, 2 and 3)

"Branching scenarios in a case study explores our entire potential outcomes." "enjoyable experience when studying with no pressure from the instructor and the other students." (FG 4, 5 and 6)

\subsection{Innovative Navigation}

During the interview with the participants, the focus group commented that e-learning encouraged them to read and view answers using critical thinking and evidence-based practice, especially in solving scenario-based questions. 
"Though scenario-based questions from the case study have innovation, we feel that e-learning helped to prepare us for the theoretical perspectives of the professional body of knowledge but not clinical experiences." (FG 4 and 5)

"Clinical training is mandatory, that could be achieved only in the presence of patients." (FG 2 and 3)

"Feeling embarrassed due to the occasion of submitting wrong responses, which makes us lose our degrees. We faced struggles due to internet difficulties. (FG 1 and 6)

\subsection{High Stakes Versus Low stakes Assignments}

Students revealed that they were better prepared for high stakes assessment by providing them with frequent ongoing and timely low-stakes assignments as a formative evaluation. Besides, they expressed that these low-stakes assignments using six weeks of successive online mini-quiz offered students an indicator to reveal their performance while taking a course and motivating their proficiency before receiving a final grade.

"We shall have Quizzes and tests with automatic grading. Not only that, but we also need instant feedback on the answer. Instead of just flagging an answer as "wrong," include an explanation in our quiz that will help us understand the rationale for the wrong answer to direct us to a module where we might learn more." "It would be more likely to obtain the good scores if we are allowed to backtrack and the possible attempt to log in attending the online test.' (Final written Theory Exam) (FG 6)

E-learning provides us dual benefits: "to improve learning and to provide support." (All FG)

Low Stake Assessment: "every week, quizzes are likely to be more critical in providing support to acquire the desired grades, whereas quality and dynamics of interactions may be the more critical influencing factors in learning and educational performance." (All FG)

Finally, students had a few concerns as "First thoughts were utter fear ..... No clue no background in e-learning; I was frozen at the thought of making a PowerPoint presentation with myself in it. Sometimes the network got disconnected and experienced a cringe factor." "Though Low stake assessments we had every week, results are delayed until final grade." (FG5)

"There is flexibility in it, and I feel... I do not have to worry about trying to find to come to campus to meet with my instructor, and there is no hassle in trying to rush to get to class and study at our own time." (FG4)

\section{Discussion}

This study intended to analyze the perception and ease among students who had BBLMS learning during the COVID19 situation. It was evident that e-learning strategies established a supportive rapport that successfully qualifies for quality indicators for the online education system. The results aligned with the study of Rahim $2021^{(16)}$, and Fahara et al., ${ }^{(17)}$ who indicated similar qualities such as time spent in the learning atmosphere, days posted (Course content) on the portal, the number of feedback made to students within a discussion, and timeliness of responses to students' questions and grading of assignments considered as a measure of quality. Students revealed verbal immediacy by calling the students by name, using humor, and encouraging students' input and discussion. Walkem demonstrated that E-learning encourages many online participants to continue their learning on their own time. Our focus group participants also pointed out that e-learning is a motivating driving force for learning continuously ${ }^{(18)}$.

E-learning initially in Saudi Arabia was further supported in the subsequent years with computer technology expansion and the World Wide Web ${ }^{(19)}$. Since 2006, the Saudi Arabia government started encouraging the e-learning platforms implementation, which substantially shifted traditional face-to-face methods into more technology ${ }^{(20)}$. E-learning can enhance educational reform by creating a transition from teacher cantered and memory-based education to student-focused education where students work collaboratively, construct their knowledge, and enhance their critical thinking ${ }^{(21)}$.

Although this process is at the nascent stage of innovation at a faculty of nursing in Saudi Arabia, students believed that communication using online platforms could offer new ways of interacting with peers and teachers. Godwin and Kelvin documented that an online ${ }^{(22)}$ learning environment is characterized by social collaboration, an atmosphere that increases students' self-confidence in interaction and self-esteem, and the ability to voice opinions online than the face-to-face method of learning. A study by Back DA et al. also insisted on the influential underlying factors in enhancing technological programs' efficiency ${ }^{(23)}$.

Moreover, students had no previous experiences or exposure to any e-learning strategy; hence there were concerns expressed about competency in the new Blackboard system to be employed, particularly with the preparation of student's presentation on a case study. However, they viewed e-learning experiences related to assessment methods using low-stakes assignments established by the institution to obtain their desired degree ${ }^{(24)}$.

There are many advantages to e-learning, including asynchronous learning and its technologies that reflect real-time knowledge. Instructors facilitate live discussions and lectures with students that involve self-paced or self-contained learning 
and offer greater flexibility than the synchronous learning approach. A study by Kahn $\mathrm{P}$ et al. mentioned that online learning provides plenty of opportunities to deliver services for people continuing their education, leverage technology to reduce the burden on teachers, and use improved pedagogies better suited to preserving student engagement ${ }^{(25)}$. Moreover, students who might not necessarily be interested in real-time interactions, but just the acquisition of knowledge, might also opt for an asynchronous learning approach, enabling them to study at their own pace, which is not in the case of the conventional classroom setting ${ }^{(26)}$.

Focus group students expressed many of these advantages and disadvantages noted in the literature. While immediately receiving grades in a few weeks was outstanding, the immediacy of feedback, too, was considered advantageous. They deemed e-learning a learning tool to review case-based scenarios, thus broadening and strengthening their strengths and deficits. A study by Naomi Holmes ${ }^{(27)}$ supported these findings as a commonly used method (frequent assessment) to overcome low self-esteem, low motivation, inappropriate study behaviors, and anxiety.

A few students referred to the use of social media in communication to facilitate interaction. This insight is compatible with the study that describes social media that has increasingly been integrated into the higher education learning experience and shown to stimulate student's engagement and collaborative work ${ }^{(28)}$. Online education using innovative technologies and evidence-based teaching (Case-based Scenarios) have the outstanding potential to motivate nursing students to seek knowledge as they make an effort to sort out the problem or derive a conclusion. Teachers are instead making an effort to push students to pull out the information; a scenario can generate the student's need to utilize it ${ }^{(29)}$. Innovative strategies can promote critical and creative thinking skills, and their use in online education can help enhance the student experience ${ }^{(30)}$. Another study insisted that neither the faculties nor all the students sensitized online teaching when lockdown started, using Zoom or other platforms. ${ }^{(31)}$. Hence, the e-learning of BBLMS simple, clear, and motivate the learners to use it effectively ${ }^{(32)}$.

Our study's major strength is that the crucial factor contributing to students' experience was the flexible class participation time and individual attention via the Blackboard system's chatbox and mail correspondence system. The flexibility of online education has been widely recognized as one advantage and plans their work and study at their own time. Students could log in to the online course at any time when they are available.

\section{Conclusion}

These findings provide insights into how educators and administrators can successfully capture essential information to prepare their students to implement blackboard learning. The BLMS of online learning's globally adopted system successfully succeeded the challenges by appropriate training to trainers and students as an alternative platform during the pandemic crisis. Nevertheless, increasing the number of low-stakes assessments and creating various online flexible assessment tools to facilitate the strategic development of e-learning could encourage students to impact reality outcomes. More explicitly, focus on test preparation and test-taking strategies that can enhance reflection upon how they prepare for and engage in future e-learning.

The study population was restricted to one course of undergraduate nursing students enrolled in one department of higher education institutions in Saudi Arabia, limiting the study findings' overall generalizability.

\section{References}

1) Chen C. Students' perceptions about e-learning in higher education institution A-Case Study. 2016. Available from: https://repository.stcloudstate.edu/ im_etds/8/.

2) Basak SK, Wotto M, Bélanger P. E-learning, M-learning and D-learning: Conceptual definition and comparative analysis. E-Learning and Digital Media. 2018;15(4):191-216. Available from: https://dx.doi.org/10.1177/2042753018785180.

3) Nahla AT, Pushpamala R, Mohammad SA, Fatmah JA, Grace ML, Sana AA, et al. Asfour Hayam I. Faculty members' readiness implementing e-learning in higher education Saudi Universities: A cross-sectional study. Indian Journal of Science and Technology. 2020;13(25):2558-2564. Available from: https://doi.org/10.17485/IJST/v13i25.828.

4) The Covid-19 pandemic has changed education forever. World Economic Forum. 2020.

5) Kahn P, Everington L, Kelm K, Reid I, Watkins F. Understanding student engagement in online learning environments: the role of reflexivity. Educational Technology Research and Development. 2017;65:203-218. Available from: https://dx.doi.org/10.1007/s11423-016-9484-z.

6) Kala S, arun Isaramalai S, Pohthong A. Electronic learning and constructivism: A model for nursing education. Nurse Education Today. 2010;30(1):61-66. Available from: https://dx.doi.org/10.1016/j.nedt.2009.06.002.

7) Arab News 2020. 2020. Available from: https://www.arabnews.com/node/1645091/middle- east2020.

8) Abbasi S, Ayoob T, Malik A. Shabnam Iqbal Memon. Perceptions of students regarding E-learning during Covid-19 at a private medical college. Pakistan Journal of Medical Science. 2020;36:19-23. doi:10.12669/pjms.36.COVID19-S4.2766.

9) Frazer C, Sullivan DH, Weatherspoon D, Hussey L. Faculty Perceptions of Online Teaching Effectiveness and Indicators of Quality. Nursing Research and Practice. 2017;p. 1-6. Available from: https://dx.doi.org/10.1155/2017/9374189.

10) Alharbi HA, Almutairi AF, Alhelih EM, Alshehry AS. The Learning Preferences among Nursing Students in the King Saud University in Saudi Arabia: A Cross-Sectional Survey. Nursing Research and Practice. 2017;p. 1-7. Available from: https://dx.doi.org/10.1155/2017/3090387. 
11) Stephanie JB, Claire M. Student Experiences in Online Courses: A Qualitative Research Synthesis. Quarterly Review of Distance Education;13(2):77-85. Available from: https://eric.ed.gov/?id=EJ1005840.

12) Shahmoradi L, Changizi V, Mehraeen E, Bashiri A, Jannat B, Hosseini M. The challenges of E-Learning system: Higher educational institutions perspective. Journal of Education and health promotion. 2018;7(116). doi:10.4103/jehp.jehp_39_18.

13) Wu FL, Tai HC, Sun JC. Self-management Experience of Middle-aged and Older Adults With Type 2 Diabetes: A Qualitative Study. Asian Nursing Research. 2019;13(3):209-215. Available from: https://dx.doi.org/10.1016/j.anr.2019.06.002.

14) Liang SY, Chuang YH, Wu SF. Preliminary application of content analysis to qualitative nursing data. Journal of Nursing. 2012;59(5):84-90. doi:10.6224/JN.59.5.84.

15) Lorelli S, Nowell JM, White DN, Moulles JN. Thematic analysis: Striving to meet the trustworthiness criteria. International Journal of qualitative methods. 2017;16:1-13. Available from: https://doi.org/10.1177/1609406917733847.

16) Rahim MN, Chandran SSC. Investigating EFL Students' Perceptions on E-learning Paradigm-Shift During Covid-19 Pandemic. Elsya : Journal of English Language Studies. 2021;3(1):56-66. Available from: https://dx.doi.org/10.31849/elsya.v3i1.5949.

17) Fahara MF, Castro AL. Teaching Strategies to Promote Immediacy in Online Graduate Courses. Open Praxis. 2015;7(4):363-376. Available from: https://dx.doi.org/10.5944/openpraxis.7.4.228.

18) Walkem K. Instructional immediacy in elearning. Collegian. 2014;21(3):179-184. Available from: https://dx.doi.org/10.1016/j.colegn.2013.02.004.

19) Gawad AMA, Al-Masaud AKK. Impediments of Activating E-Learning in Higher Education Institutions in Saudi Arabia. International Journal of Advanced Computer Science and Applications. 2014;5(4):12-18. Available from: https://dx.doi.org/10.14569/ijacsa.2014.050403.

20) Alshehri AM. Quality management and medical education in Saudi Arabia. Quality management and practices. 2012;p. 67-86.

21) Salah AF. Students' perception of e-learning in Arab society: Kuwait University as a case study. E- Learning. 2018;5(4):418-428.

22) Kaisara G, Bwalya KJ. Investigating the E-Learning Challenges Faced by Students during Covid-19 in Namibia. International Journal of Higher Education. 2020;10(1):308-308. Available from: https://dx.doi.org/10.5430/ijhe.v10n1p308.

23) Back DA, Behringer F, Haberstroh N, Ehlers JP, Sostmann K, Peters H. Learning management system and e-learning tools: an experience of medical students' usage and expectations. International Journal of Medical Education. 2016;7:267-273. Available from: https://dx.doi.org/10.5116/ijme.57a5.f0f5.

24) Warnock S. Frequent, low stakes grading: Assessment for communication, confidence. Faculty focus. Madison, WI. Magna Publications. 2013.

25) Kahn P, Everington L, Kelm K, Reid I, Watkins F. Understanding student engagement in online learning environments: the role of reflexivity. Educational Technology Research and Development. 2017;65:203-218. Available from: https://dx.doi.org/10.1007/s11423-016-9484-z.

26) More NB. Student attitude towards the integration of you tube in online, hybrid, and web assisted courses: An examination of the impact of course modality on perception. Journal of Online Learning and Teaching. 2015;11(1):55-73.

27) Holmes N. Student perceptions of their learning and engagement in response to the use of a continuous e-assessment in an undergraduate module. Assessment \& Evaluation in Higher Education. 2015;40:1-14. Available from: https://dx.doi.org/10.1080/02602938.2014.881978.

28) Rigby L, Wilson I, Baker J, Walton T, Price O, Dunne K. The development and evaluation of a 'blended' enquiry based learning model for mental health nursing students: "making your experience count". Nurse Education Today. 2012;32(3):303-308. Available from: https://dx.doi.org/10.1016/j.nedt.2011. 02.009 .

29) Kohnke L, Moorhouse BL. Adopting HyFlex in higher education in response to COVID-19: students' perspectives. Open Learning: The Journal of Open, Distance and e-Learning. 2021;p. 1-4. Available from: https://doi.org/10.1080/02680513.2021.1906641.

30) Arbour MW, Nypaver CF, Wika JC. Innovative Uses of Technology in Online Midwifery Education. Journal of Midwifery \& Women's Health. 2015;60(3):278-282. Available from: https://dx.doi.org/10.1111/jmwh.12291.

31) Roy H, Roy K, Saha S. Asis Kumar Ghosal. Study on Students' Perceptions for Online Zoom-app Flipped Class Sessions on Anatomy Organised during the Lockdown Period of Covid-19 Epoch. Journal of Clinical and Diagnostic Research. 2020;14(6):1-4.

32) Tayyib NA, Ramaiah P, Alshmemri MS, Ali HYS, Asfour HI, Alsolami FJ, et al. Attitude of Faculty members towards E-Learning in Saudi Universities: A Cross Sectional Study. Journal of Liaquat University of Medical and Health Sciences. 2020;19(4):291-296. 